\title{
Hiperfortunas y superricos: ¿por qué tiene sentido un impuesto al patrimonio? ${ }^{1}$
}

\author{
Ramón E. López y Gino Sturla
}

Mientras el COVID-19 golpea al mundo, los millonarios como nosotros tenemos un papel fundamental en la curación de nuestro mundo. [...]

A diferencia de decenas de millones de personas en todo el mundo, nosotros no tenemos que preocuparnos por perder el trabajo, la casa o la capacidad de mantener a nuestra familia. [...]

Por favor, cóbrennos más impuestos. Háganlo. No lo duden. Es la opción correcta. Es la única opción. La humanidad es más importante que nuestro dinero.

Arthur y otros (2020)

\section{Resumen}

Se propone aquí un modelo para estimar la riqueza de los grupos más ricos de la sociedad y diseñar un sistema eficiente de impuesto patrimonial. Para las consideraciones de diseño e implementación se revisa la experiencia internacional comparada y se presenta una discusión analítica de los efectos del impuesto patrimonial, examinando las principales críticas que han recibido por parte de economistas ortodoxos. La metodología asociada al cálculo del patrimonio considera aproximaciones de primer orden y el criterio de Pareto para abordar las limitaciones en los datos, y se plantea un sistema impositivo que corrige los problemas que se han presentado en la implementación de este tipo de tributos en otros países. El modelo se aplica a la realidad de Chile que, al igual que otros países de la región, presenta una desigualdad estructural en la concentración del ingreso y la riqueza que se ha visto amplificada por los efectos del COVID-19.

\section{Palabras clave}

Riqueza, medición, tributación, impuesto a la renta, impuesto a la propiedad, recaudación de impuestos, política fiscal, distribución del ingreso, igualdad, desarrollo económico, estudios de casos, Chile

\section{Clasificación JEL}

$$
\text { D31, H24, E62 }
$$

\section{Autores}

Ramón E. López es Profesor Titular del Departamento de Economía de la Facultad de Economía y Negocios (FEN) de la Universidad de Chile. Correo electrónico: ramlopez@fen.uchile.cl.

Gino Sturla es Doctor en Economía, Departamento de Economía y Administración de la Universidad de Florencia. Correo electrónico: ginostefano.sturlazerene@unifi.it. 


\section{Introducción}

La crisis causada por el COVID-19 ha sido considerada la peor de las últimas décadas tanto desde el punto de vista sanitario como económico. Este estudio comienza con la formulación de tres preguntas clave.

¿Quiénes han sufrido el impacto de esta crisis? La gran mayoría de la población se ha visto afectada por enormes sufrimientos físicos, grandes pérdidas económicas e incluso la muerte. Los sectores de bajos ingresos y las capas medias han sufrido un embate socioeconómico sin precedentes que supone un retroceso de muchos años en su bienestar. La pobreza se ha acrecentado rápidamente y una parte de la población ha llegado a sufrir hambre y a depender de ollas comunes. Trabajadores, pobladores y pequeños comerciantes han sido particularmente afectados por esta crisis que ha causado altísimas tasas de desempleo, significativas bajas de los salarios reales y el colapso de innumerables pequeñas y medianas empresas (pymes).

¿Quiénes han financiado los enormes costos económicos de esta crisis? En primer lugar, los trabajadores y las capas medias, que han debido recurrir a sus exiguos ahorros para poder sobrevivir. Esto ha implicado una reducción significativa de los fondos acumulados para pensiones de vejez y un descenso casi total de los fondos de cesantía. Además, las medidas de los gobiernos han llevado a grandes déficits fiscales, de una envergadura que en muchos países no se veía desde hacía muchas décadas, mayor endeudamiento fiscal y una reducción de los fondos soberanos. Es importante señalar que de no mediar grandes cambios tributarios a mediano plazo, y tal como ha ocurrido en innumerables crisis anteriores, los trabajadores y las pymes serán fundamentalmente los que pagarán los déficits fiscales y el aumento de la deuda.

¿Quiénes no han sufrido los embates de esta crisis y tampoco han contribuido al financiamiento de sus costos? Principalmente los grupos que registran mayores niveles de riqueza e ingresos, que, lejos de sufrir los efectos de la pandemia, han visto su riqueza aumentada de manera significativa. Según un estudio de Oxfam (Ruiz, 2020), la fortuna de los milmillonarios en América Latina aumentó más de 48.000 millones de dólares hacia fines de 2020, en un momento de gran crisis y notables sufrimientos para el resto de la población.

He aquí la principal justificación por la cual en muchos países de la región se ha propuesto la implantación de un impuesto al patrimonio de las grandes fortunas que permita aliviar la gran carga que supone financiar los efectos económicos de esta crisis para el resto de la población. Si los superricos, que se han beneficiado enormemente del modelo económico neoliberal prevaleciente y que han tenido una carga tributaria desproporcionadamente pequeña en comparación con sus cuantiosos ingresos y fortunas, no contribuyen a financiar esta gran crisis, la percepción generalizada de injusticia se va a acrecentar aún más en los países de la región. Esto podría llevar a una creciente inestabilidad social y política que, a su vez, podría generar aún más sufrimiento para la población y una mayor profundización de la crisis económica en el mediano plazo².

A raíz de la crisis sanitaria, la discusión sobre el impuesto patrimonial ha ganado fuerza en prácticamente todos los países de la región: Argentina, Brasil, Chile, Ecuador, Paraguay y Perú. Los efectos de la pandemia del COVID-19 son regresivos, ya que afectan de manera sensible a los que menos tienen, no solo en su salud sino también en su economía. Esto implica una profundización de la desigualdad, a menos que el Estado revierta, o al menos compense, la situación. El cumplimiento de las funciones del Estado tiene dos pilares: la forma de recaudar tributos y las decisiones de ejecución del gasto (Strada y otros, 2020).

\footnotetext{
2 Oxfam ha planteado que los gobiernos de la región están infragravando tanto la riqueza personal como los beneficios empresariales, lo que socava su lucha contra el COVID-19, la pobreza y la desigualdad. También ha propuesto la aplicación de un impuesto al patrimonio en toda la región, para fortunas netas de más de 1 millón de dólares, con tasas progresivas del $2 \%$ al 3,5\% (Ruiz, 2020).
} 
Los impuestos al patrimonio han existido por mucho tiempo en prácticamente todos los países del mundo. Los impuestos patrimoniales tradicionales, que incluyen impuestos a la propiedad física (casas, tierra y demás), impuestos a la herencia y otros existen en casi todos los países y, como se muestra en este artículo, en algunos de ellos constituyen una proporción significativa de la recaudación tributaria. Existe otra categoría de impuestos al patrimonio, que aquí se denomina impuestos patrimoniales no tradicionales, que gravan patrimonios financieros y otras formas de riqueza, incluidos patrimonios bursátiles, entre otros. Los impuestos patrimoniales no tradicionales son mucho menos frecuentes, actualmente se aplican en un número limitado de países y han sido objeto de críticas por parte de economistas ortodoxos y algunos encargados de la formulación de políticas. Los impuestos patrimoniales globales corresponden a la suma de los tradicionales y los no tradicionales.

En este artículo se realiza un profundo análisis de los impuestos patrimoniales, con especial énfasis en los impuestos patrimoniales no tradicionales. Además, se provee una metodología para estimar la recaudación posible y una manera de determinar su focalización en grupos de la población de muy alta riqueza. Al mismo tiempo, se discuten características para su diseño e implementación a fin de reducir los principales problemas que la aplicación de estos impuestos ha tenido en otros países, de modo de disminuir su exposición a las críticas más importantes que han recibido. Se ponen los impuestos patrimoniales no tradicionales en el contexto de los impuestos patrimoniales globales, desagregando la recaudación de estos últimos en impuestos patrimoniales tradicionales y no tradicionales en los países donde ambos tipos de impuestos patrimoniales coexisten.

\section{Motivación: el caso de Chile}

Los impuestos patrimoniales constituyen una temática especialmente particular en el caso de Chile por varias razones.

En primer lugar, a diferencia de otros países, en Chile la crisis sanitaria se da poco tiempo después de la crisis social surgida del estallido social de octubre de 2019. Este conflicto se ha mantenido vigente de una manera subyacente, fundamentalmente por dos razones: porque las demandas sociales que lo gatillaron no han sido en absoluto satisfechas y porque la crisis sanitaria no ha hecho más que agravar las enormes carencias sociales y la vulnerabilidad de ciertos sectores de la sociedad. Dada la intensidad de la crisis actual, si no se toman medidas urgentes de apoyo a los sectores más afectados por enormes pérdidas de ingreso, las cifras de pobreza del país podrían llegar al 50\% de la población y causar una espiral de violencia con consecuencias difíciles de prever.

En segundo lugar, como se verá más adelante, los niveles de desigualdad y, sobre todo, de concentración de la riqueza en Chile son abismales, tal vez de los más altos del mundo. Esto vuelve más relevante aún el planteo de los impuestos a la riqueza que tienen el potencial de corregir esta desigualdad en sus raíces más profundas.

En tercer lugar, a pesar de esta profunda desigualdad, la carga tributaria del país es una de las más bajas de los países de la Organización de Cooperación y Desarrollo Económicos (OCDE). El sistema tributario incluso ha tratado los ingresos provenientes del capital con extraordinaria preferencia, evitando prácticamente la aplicación de regalías sobre las rentas económicas, y las ganancias de capital casi no están sujetas a impuestos.

En cuarto lugar, desde el inicio de la crisis sanitaria del COVID-19 el país se ha visto enfrentado a dos visiones dominantes: la del gobierno, que tiende a imponer demasiadas condiciones para acceder a la ayuda social, y la de ciertos sectores progresistas, que han postulado la necesidad de un apoyo social más laxo, recurriendo a deuda fiscal o a los fondos soberanos. Si bien la segunda alternativa hubiera generado consecuencias económicas y sociales menos dramáticas, continúa con la lógica de 
que en el corto y mediano plazo los costos de las crisis los pagarán los sectores medios y de menores ingresos, percepción generalizada en la población y amplificada por las condiciones sociales existentes desde octubre de 2019.

En quinto lugar se destaca que la deficiencia en materia de apoyo estatal a los sectores vulnerables se ha traducido en la cuantiosa utilización de los fondos de cesantía de los trabajadores y en el retiro de los fondos de pensiones. Esta última medida concitó un gran apoyo en la ciudadanía, recogido por toda la oposición e incluso parte del oficialismo. Sin perjuicio de los beneficios de corto plazo para la población, aquí los recursos provienen de los mismos trabajadores, en ningún caso se obtienen de los sectores de la población que tienen mayores fortunas.

En sexto lugar, el gobierno definió, junto con un grupo de economistas ortodoxos, un plan de activación económica denominado Acuerdo por la Protección Social y Recuperación del Empleo que, pese a las resistencias iniciales, fue aprobado por la oposición ${ }^{3}$. Este acuerdo incluye un Marco Fiscal que, grosso modo, contempla unos 12.000 millones de dólares a ejecutar en 24 meses. En la lógica del punto quinto, este plan tampoco supone acuerdos relativos a cambios tributarios que permitan evitar la sensación ya mencionada de que "las crisis las pagamos todos".

En séptimo lugar, en junio del 2020 se presentó un proyecto de reforma constitucional en la Cámara de Diputados de Chile para el establecimiento de un impuesto a los superricos, por única vez ${ }^{4}$. El proyecto cuenta con un alto respaldo ciudadano (CELAG, 2020) y ha tenido buena acogida entre los parlamentarios de la oposición, generando votaciones históricas. Aun así, algunos economistas ortodoxos que dicen representar al progresismo se oponen férreamente en virtud de las críticas que se mencionan más adelante.

Si se consideran estos siete puntos, resulta claro que el país convivirá con una deuda financiera externa y, más importante aún, con una deuda social con todos los trabajadores y las pymes que han pagado con sus ahorros los costos de la crisis y que seguirán pagándolos con sus impuestos.

El costo fiscal del apoyo social puede llegar a 15.000 millones de dólares (casi un 6\% del PIB). La cuestión fundamental -y coherente con lo ya mencionado - es que una parte significativa de ese financiamiento debe venir de una contribución de los sectores más ricos de la población, entre los que se constata que los milmillonarios (sobre 1.000 millones de dólares) han aumentado un $27 \%$ su fortuna durante la crisis del COVID-19 (Ruiz, 2020).

Una parte importante del apoyo social necesario debe provenir de las más grandes fortunas. En este trabajo se propone un mecanismo para esta contribución que implique un impuesto patrimonial no tradicional de mucha simplicidad dirigido a un pequeño grupo de ricos y superricos (el $0,07 \%$ de la población adulta) $)^{5}$.

\footnotetext{
3 Véase CPI (2020).

4 Véase [en línea] https://www.camara.cl/verDoc.aspx?prmID=13876\&prmTIPO=INICIATIVA.

5 En los Estados Unidos, el 0,1\% de la población adulta concentra un 20\% de la riqueza privada total (Saez y Zucman, 2019a). En Chile, como se estima en este trabajo, el 0,07\% concentra un 34\% (el porcentaje de la población adulta chilena se obtiene de INE (2020)).
} 


\section{Examen de la experiencia comparada}

\section{Impuestos patrimoniales en otros países}

Actualmente ocho países de la OCDE y de América Latina aplican impuestos patrimoniales no tradicionales de diversa magnitud. En el cuadro 1 se presentan los aspectos más importantes asociados a cada uno de los sistemas de los países que aplican un impuesto sobre la riqueza financiera: tipo de patrimonio afecto, monto exento, tasas, recaudación como proporción del PIB y de la recaudación total, y si el impuesto tiene - o no- efecto sobre las capas medias y medias altas.

Cuadro 1

Experiencia comparada de la aplicación del impuesto patrimonial no tradicional

\begin{tabular}{|c|c|c|c|c|c|c|}
\hline País & Patrimonio afecto & Monto exento & $\begin{array}{c}\text { Tasas } \\
\text { (en porcentajes) }\end{array}$ & $\begin{array}{c}\text { Recaudación } \\
\text { (en porcentajes } \\
\text { del PIB) }\end{array}$ & $\begin{array}{l}\text { Recaudación } \\
\text { (en porcentajes de } \\
\text { la recaudación total) }\end{array}$ & $\begin{array}{l}\text { Efecto sobre } \\
\text { capas medias } \\
\text { y medias altas }\end{array}$ \\
\hline España & $\begin{array}{l}\text { Patrimonio total } \\
\text { (personas naturales) }\end{array}$ & $\begin{array}{l}760000 \text { dólares } \\
325000 \text { dólares } \\
\text { vivienda habitual }\end{array}$ & $\begin{array}{l}0,15 \\
a \\
3,75\end{array}$ & 0,18 & 0,50 & No \\
\hline Noruega & $\begin{array}{l}\text { Patrimonio total } \\
\text { (personas naturales } \\
\text { y jurídicas) }\end{array}$ & 146000 dólares & 0,85 & 0,45 & 1,10 & Sí \\
\hline Suiza & $\begin{array}{l}\text { Patrimonio total } \\
\text { (personas naturales } \\
\text { y jurídicas) }\end{array}$ & $\begin{array}{l}\text { Entre } 50000 \text { dólares } \\
\text { y } 250000 \text { dólares, } \\
\text { según integrantes } \\
\text { del hogar }\end{array}$ & $\begin{array}{l}0,30 \\
1,00\end{array}$ & 1,09 & 3,90 & Sí \\
\hline Luxemburgo & $\begin{array}{l}\text { Patrimonio total } \\
\text { (personas jurídicas) }\end{array}$ & $\begin{array}{l}\text { Ciertos activos: } \\
\text { participaciones calificadas } \\
(10 \%) \text { y derechos de } \\
\text { propiedad intelectual }\end{array}$ & $\begin{array}{l}0,05 \\
0,5\end{array}$ & 2,90 & 9,35 & No \\
\hline Bélgica & $\begin{array}{l}\text { Patrimonio financiero } \\
\text { (personas naturales) }\end{array}$ & 550000 dólares & 0,15 & 0,21 & 0,88 & No \\
\hline Colombia & $\begin{array}{l}\text { Patrimonio total } \\
\text { (personas naturales } \\
\text { y jurídicas) }\end{array}$ & $\begin{array}{l}140500 \text { dólares, } \\
\text { vivienda habitual }\end{array}$ & 1,00 & 0,40 & 2,76 & No \\
\hline Uruguay & $\begin{array}{l}\text { Patrimonio total } \\
\text { (personas naturales } \\
\text { y jurídicas) }\end{array}$ & $\begin{array}{l}\text { Bienes agrícolas y } \\
\text { rurales, activos en el } \\
\text { exterior y títulos de deuda } \\
\text { pública. Sin tope. }\end{array}$ & $\begin{array}{l}0,40 \\
0,70 \\
1,50\end{array}$ & 1,00 & 4,98 & Sí \\
\hline Argentina & $\begin{array}{l}\text { Patrimonio bruto } \\
\text { (personas naturales } \\
\text { y jurídicas) }\end{array}$ & $\begin{array}{l}300000 \text { dólares } \\
\text { Primera vivienda y otros } \\
\text { activos (saldos de plazos } \\
\text { fijos, títulos de deuda } \\
\text { emitidos por el Estado y } \\
\text { bienes inmateriales como } \\
\text { marcas y patentes) }\end{array}$ & $\begin{array}{l}0,25 \\
a \\
2,25\end{array}$ & 0,20 & 0,61 & No \\
\hline
\end{tabular}

Fuente: Elaboración propia, sobre la base de Organización de Cooperación y Desarrollo Económicos (OCDE), "Revenue Statistics - OECD countries: comparative tables: comparative tables - OECD countries", 2019 [en línea] https://stats.oecd.org/ Index.aspx?Queryld=21699; Organización de Cooperación y Desarrollo Económicos (OCDE), The Role and Design of Net Wealth Taxes in the OECD, OECD Tax Policy Studies, № 26, París, 2018; Comisión Económica para América Latina y el Caribe (CEPAL), Panorama Fiscal de América Latina y el Caribe, 2017 (LC/PUB.2017/6-P), Santiago, 2017; Agencia Argentina de Inversiones y Comercio Internacional (AAICl), "El sistema tributario en la Argentina", 2019 [en línea] https:// www.inversionycomercio.org.ar/docs/pdf/EI_Sistema_Tributario_en_la_Argentina.pdf; KMPG International, Tax Facts 2020: a Survey of the Norwegian Tax System, 2020 [en línea] https://assets.kpmg/content/dam/kpmg/no/pdf/2020/03/ Tax-facts-2020_WEB.PDF; Harrison Brook, "Wealth tax in Spain 2020 for expats", 3 de junio de 2019 [en línea] https:// www.harrisonbrook.co.uk/wealth-tax-spain-2018/; The Norwegian Tax Administration, "Wealth tax", 2020 [en línea] https://www.skatteetaten.no/en/rates/wealth-tax/?year=2020\#rateShowYear; E. Asen, "Wealth taxes in Europe", Tax Foundation, 20 de noviembre de 2019 [en línea] https://taxfoundation.org/wealth-tax-europe/, y C. Barría, "Los 3 países de América Latina que cobran impuesto a la riqueza (y qué resultados han tenido)", BBC News, 17 de enero de 2020 [en línea] https://www.bbc.com/mundo/noticias-51099710. 
En el gráfico 1 se presenta la recaudación del impuesto patrimonial no tradicional respecto de la recaudación impositiva total de cada país. Como puede apreciarse, los impuestos patrimoniales han contribuido, en algunos países de manera significativa, a la recaudación tributaria, alcanzando un promedio de más del $3 \%$ del total recaudado.

\section{Gráfico 1}

OCDE y América Latina (países seleccionados): recaudación del impuesto patrimonial no tradicional como proporción de la recaudación impositiva total, 2017-2018

(En porcentajes)

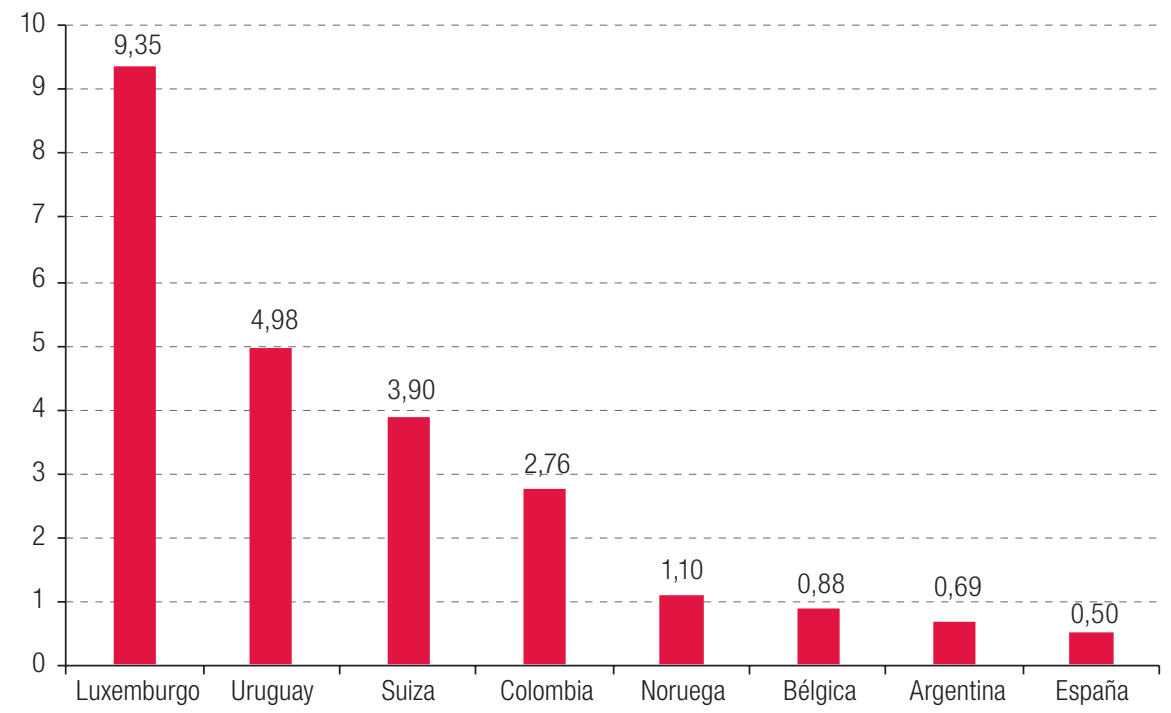

Fuente: Elaboración propia, sobre la base de Organización de Cooperación y Desarrollo Económicos (OCDE), "Revenue Statistics - OECD countries: comparative tables: comparative tables - OECD countries", 2019 [en línea] https://stats. oecd.org/Index.aspx?Queryld=21699, y Comisión Económica para América Latina y el Caribe (CEPAL), Panorama Fiscal de América Latina y el Caribe, 2017 (LC/PUB.2017/6-P), Santiago, 2017.

Nota: Mientras que para Colombia y el Uruguay los montos corresponden a 2017, para el resto de los países corresponden a 2018.

En el gráfico 2 se presenta una comparación de los impuestos patrimoniales globales para los países analizados y otros que tienen impuestos patrimoniales tradicionales bastante parecidos a los no tradicionales, con otros nombres o formas, además de Chile ${ }^{6}$. En la lista de países considerados no solo se incluyen países de altos niveles de desarrollo, sino también varios con niveles de ingreso similares o aún más bajos que Chile. Se observa que Chile presenta el valor de impuestos patrimoniales globales más bajo; esto es, además de no tener un impuesto patrimonial no tradicional, los impuestos patrimoniales globales son más bajos que en todos los demás países considerados.

6 De acuerdo con OCDE (2020), el impuesto sobre la propiedad se define como impuestos recurrentes y no recurrentes sobre el uso, la titularidad o la transferencia de la propiedad. Estos incluyen impuestos sobre bienes inmuebles o patrimonio neto, impuestos sobre el cambio en la titularidad de los bienes a través de herencias o donaciones, e impuestos sobre transacciones financieras y de capital. 


\section{Gráfico 2}

OCDE y América Latina (países seleccionados): recaudación del impuesto patrimonial global como proporción del PIB, promedio 2008-2017

(En puntos porcentuales)

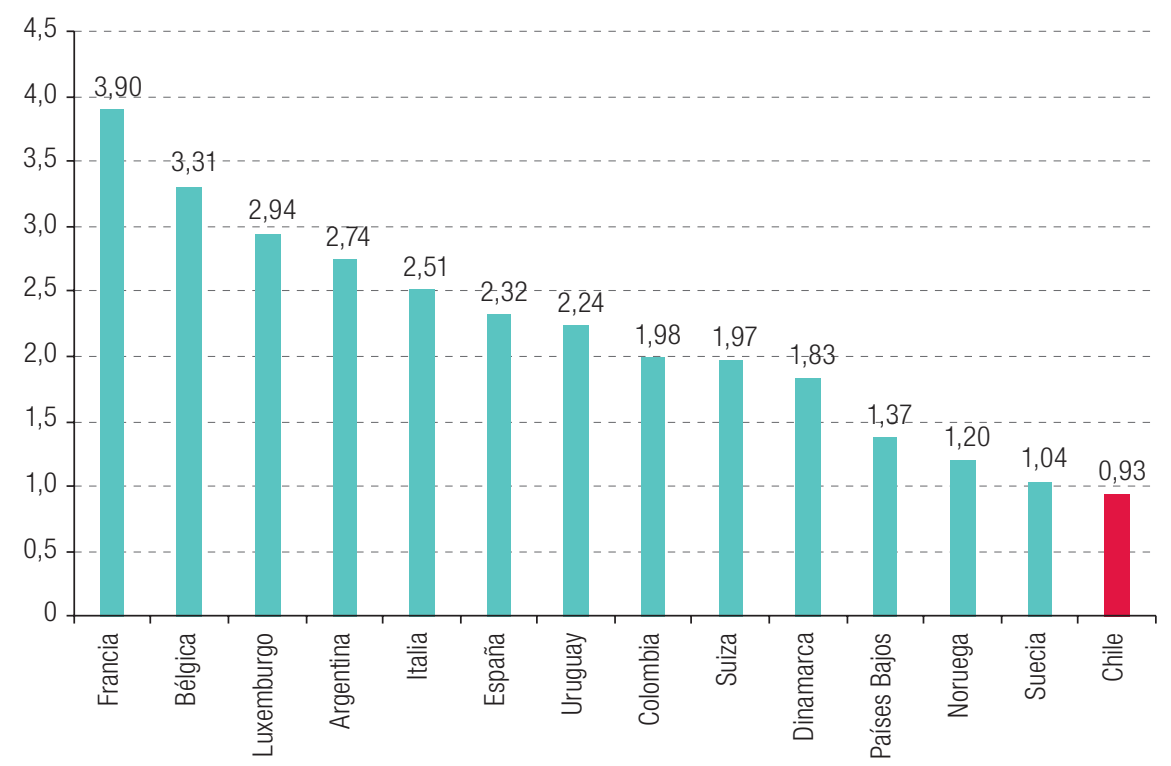

Fuente: Elaboración propia, sobre la base de Organización de Cooperación y Desarrollo Económicos (OCDE), "Revenue Statistics - OECD countries: comparative tables: comparative tables - OECD countries”, 2019 [en línea] https://stats. oecd.org/Index.aspx?Queryld=21699.

\section{Otros casos de interés}

En Francia, en 2017, se eliminó el impuesto patrimonial no tradicional y se pasó a gravar solo a los activos inmobiliarios; la recaudación en ese año ascendió al 0,2\% del PIB y en 2018 fue del 0,1\% del PIB (OCDE, 2019a). Si bien la OCDE (2019a) lo sigue considerando en sus informes como un impuesto a la riqueza, a los efectos de este estudio no se ha considerado como un impuesto patrimonial no tradicional, en virtud, sobre todo, de que el impuesto patrimonial global de Francia es el más alto en la OCDE (en 2018 llegó al 4,4\% del PIB).

Dinamarca y Suecia han registrado tasas muy bajas de elusión y evasión del impuesto patrimonial (no tradicional) durante el período en que dicho impuesto estuvo vigente. En Suecia el impuesto al patrimonio se dejó de aplicar en 2007. En Dinamarca el impuesto a la riqueza personal era el más alto de su tipo hasta que se discontinuó en 2003. La tasa impositiva marginal sobre la riqueza llegó al 2,2\% (Seim, 2017; Jakobsen y otros, 2019).

Dos importantes estudios econométricos han demostrado que un aumento del impuesto al patrimonio del 1\% reduce la riqueza declarada en menos del 1\% (Seim, 2017; Jakobsen y otros, 2019), lo que da cuenta de una alta capacidad de recaudación. Además, en ninguno de los dos estudios se detectan efectos significativos de estos impuestos sobre el ahorro y la inversión. 


\section{Discusión analítica de los impuestos patrimoniales}

\section{Críticas a los impuestos patrimoniales no tradicionales}

En esta sección se consideran las principales críticas de las que han sido objeto los impuestos patrimoniales no tradicionales. Tres han sido las principales objeciones planteadas por los economistas ortodoxos a este tipo de impuestos (véase, por ejemplo, Kopckuk en Schrager (2020), uno de los más destacados críticos).

\section{a) Los impuestos patrimoniales no tradicionales desincentivarían el ahorro y la inversión}

Una parte muy importante de las grandes fortunas se acumula en activos de uso personal, como mansiones, tierras, yates, aviones, helicópteros y paraísos fiscales, que constituyen consumo conspicuo o ahorros en gran parte improductivos para el resto de la sociedad. Por lo tanto, los impuestos patrimoniales desincentivarán el superconsumo o los ahorros en paraísos fiscales, más que los ahorros que puedan generar beneficios para la mayoría de la sociedad. Es importante indicar que los autores de este artículo no conocen ningún estudio empírico que haya demostrado que estos impuestos en realidad han afectado los ahorros. En efecto, tres estudios empíricos recientes de gran sofisticación han demostrado que estos impuestos no tienen ningún efecto sobre los ahorros (Seim, 2017; Jakobsen y otros, 2019; Londoño-Vélez y Ávila-Mahecha, 2018).

Aparte de la sólida evidencia empírica, existen razones conceptuales de magnitud para concluir que los impuestos patrimoniales que afectan a una pequeñísima fracción de la población no inciden en la inversión. En la medida en que estos impuestos no gravan la rentabilidad de las empresas, sino que solo gravan las fortunas personales, es muy improbable que tengan un efecto negativo sobre la inversión. En el caso de Chile y muchos otros países, la propiedad de las grandes empresas está muy concentrada en manos de los llamados "controladores". A menudo, el 80\% o el 90\% de las acciones están en manos de un pequeño número de accionistas ("los controladores"), que forman parte del grupo de los superricos ${ }^{7}$.

En la medida en que la rentabilidad de la inversión en estas empresas se mantenga, la inversión en ellas no tiene por qué verse afectada, aun cuando las personas afectadas por el impuesto patrimonial no tradicional vean reducidos los incentivos para invertir. Es posible que las personas afectadas por el impuesto patrimonial no tradicional tengan menos incentivos para invertir, pero los inversionistas potenciales no afectos a dicho impuesto (recordemos que el impuesto solo afectará a una pequeñísima fracción de la población) sí van a tener incentivos para invertir en proyectos rentables. El efecto del impuesto patrimonial no tradicional puede, por lo tanto, expandir el espectro de inversionistas en las grandes empresas, en lugar de reducir la inversión en proyectos rentables. Esto, a su vez, puede provocar una dispersión de la propiedad de las grandes empresas, reduciendo así su concentración, lo que puede considerarse un fenómeno positivo. Si los superricos deciden no invertir en proyectos de alta rentabilidad, van a generar un espacio para la inversión por parte de otros inversionistas de menor riqueza no afectos al impuesto patrimonial no tradicional.

\footnotetext{
7 Véanse más detalles en Echeverría, Valdivia y Acuña (2020) y Bolsa de Comercio de Santiago (2020).
} 


\section{b) Existen mejores alternativas de impuestos, sobre todo impuestos a las rentas económicas que reducirían los incentivos a la búsqueda de rentas}

Los impuestos a las rentas económicas son a futuro. Sin embargo, una importante función del impuesto patrimonial no tradicional es recuperar para la sociedad las rentas económicas de las que se ha apropiado un pequeño grupo de superricos a lo largo de muchos años en los que esas rentas no fueron gravadas. Una parte significativa de las grandes fortunas ha sido acumulada sobre la base de rentas de todo tipo, incluidos monopolios, oligopolios, el uso de información privilegiada y rentas por recursos naturales que les fueron otorgados gratuitamente ${ }^{8}$. Esta apropiación de rentas ha constituido una transferencia forzada de riqueza desde el resto de la sociedad hacia los superricos. Dicha transferencia ha sido a costa de los consumidores que han debido pagar precios monopólicos, proveedores de grandes empresas que han recibido precios monopsónicos, inversionistas pequeños y medianos que han sido explotados por el uso de información privilegiada por parte de un pequeño número de especuladores, y los ciudadanos, verdaderos dueños de los recursos naturales y el medio ambiente, que han sido privados de recibir su justo pago por el uso y abuso de estos recursos por parte de los superricos.

Esto implica que en el pasado hubiera sido deseable contar con un sistema que gravara los flujos de las rentas económicas, en cuyo caso la necesidad de impuestos patrimoniales no tradicionales sería menos clara. Sin embargo, en la mayoría de los países esto no ha ocurrido, y en Chile, ciertamente, estas rentas no han sido gravadas durante muchas décadas. Por consiguiente, empezar hoy a gravar las rentas económicas sería de gran importancia, pero no borraría las enormes apropiaciones indebidas de estas rentas ocurridas en el pasado. Por lo tanto, los impuestos patrimoniales no tradicionales no son sustitutos de impuestos a los nuevos flujos de rentas económicas, sino que son más bien complementarios a ellos, unos gravando las rentas acumuladas en el pasado y otros gravando las nuevas rentas económicas.

Si se decidiera empezar a gravar las rentas económicas a partir de ahora, sería necesario aplicar impuestos patrimoniales no tradicionales hasta recuperar las rentas que se expropiaron a muchos ciudadanos en el pasado. Esto requiere que el valor presente del flujo anual de los impuestos patrimoniales no tradicionales se iguale a la fracción del valor de riqueza de los superricos que corresponde a las rentas económicas acumuladas por ellos.

Por último, uno de los grandes beneficios de los impuestos a las rentas económicas es que reducen los incentivos para la búsqueda de rentas, lo que promueve una mayor eficiencia económica al permitir que menos recursos se desperdicien en actividades de búsqueda de rentas ${ }^{9}$. Sin embargo, este efecto de desincentivar la búsqueda de rentas es válido para los impuestos patrimoniales, ya que también reducen los beneficios acumulados producto de la obtención de rentas. Ambos tipos de impuesto son deseables y contribuyen a reducir el uso de gastos improductivos dedicados a la búsqueda de rentas, lo que aumenta la eficiencia económica.

La aplicación de impuestos al patrimonio no se justifica únicamente para generar recursos necesarios para el Estado reduciendo la desigualdad económica en su raíz más profunda y compensando por la apropiación indebida de rentas ocurridas a través de muchas décadas, sino también como instrumento para lograr una mayor eficiencia económica ${ }^{10}$.

\footnotetext{
8 Para el caso de Chile cabe mencionar un estudio sobre rentas económicas en el sector de la gran minería privada (Sturla y otros, 2018), que informa de rentas apropiadas en diez años del orden de los 120.000 millones de dólares, equivalentes al 50\% del PIB total anual del país. También existen estudios de rentas económicas en el mercado de la salud (Accorsi y Sturla, 2019).

9 Un artículo famoso y muy ortodoxo de Murphy, Shleifer y Vishny (1993) muestra las grandes dificultades y los costos que implica la búsqueda de rentas para el crecimiento económico, poniendo énfasis en los efectos negativos sobre la producción y, sobre todo, la innovación, dos elementos clave para sostener un crecimiento a largo plazo.

${ }^{10}$ En diversos estudios se han ratificado los vínculos entre rentas, desigualdad y crecimiento económico. Los trabajos de Piketty (2005 y 2015) ofrecen una visión de largo plazo y basada en datos empíricos de estos vínculos.
} 


\section{c) Dificultades de implementación y recaudación}

La principal crítica a estos impuestos es que no han recaudado lo que se esperaba debido a la dificultad que existe a la hora de valorar ciertos activos, lo que facilita la evasión. Los tres estudios empíricos aplicados a los casos de Dinamarca, Suecia y Colombia ya mencionados (Seim, 2017; Jakobsen y otros, 2019; Londoño-Vélez y Ávila-Mahecha, 2018) han mostrado que la recaudación efectiva ha estado muy en línea con lo esperado de acuerdo con el objetivo diseñado para estos impuestos.

Sin embargo, en algunos países, estos impuestos han recaudado menos de lo esperado y en otros han fracasado en gran medida por no haber recaudado lo que se esperaba. ¿Cuáles han sido los principales factores que han conspirado contra la eficacia de los impuestos patrimoniales no tradicionales en los países en que se ha intentado aplicarlos? La revisión de su uso en diversos países permite concluir lo siguiente:

- Se han dirigido a un gran número de personas y a menudo han afectado a la clase media. En muchos casos, los montos de los valores deducibles han sido muy bajos.

- Su diseño ha sido de gran complejidad, incorporando una multitud de tasas impositivas y una variedad de deducciones.

- Las tasas aplicadas han sido heterogéneas: algunos activos están sujetos a tasas muy bajas, mientras que otros reciben un tratamiento mucho menos favorable.

- Determinados impuestos se han focalizado solo en parte del patrimonio, incluso algunos solo se dirigieron a la riqueza mantenida en el país y no a la riqueza global.

El primero de estos factores ha generado gran resistencia en la población y ha vuelto a estos impuestos muy impopulares, lo que en varios casos se tradujo en el cese de su aplicación. Los otros tres factores enumerados facilitaron la evasión en gran escala, lo que condujo a bajas recaudaciones e incluso a la eliminación del impuesto.

A continuación, se hace un planteo sobre cómo se pueden subsanar estas dificultades mediante un sistema más apropiado que el utilizado en países donde se ha recaudado poco o estos impuestos han fracasado.

\section{Implementación y ventajas del sistema propuesto con respecto a la experiencia comparada}

El sistema que se propone para Chile tiende a subsanar la mayoría de los problemas de implementación que, según los críticos, se han registrado en algunas de las experiencias en otros países:

- Se considera una exención muchísimo mayor que la de los demás países (5 millones de dólares), lo que permite que no sea necesario efectuar distinciones por tipo de patrimonio a los efectos del cálculo imponible. Los bajos niveles deducibles en algunos países han hecho que la clase media se sienta afectada, lo que dificulta mucho su aplicación y fiscalización. Ninguno de estos países tiene deducibles de más de 1 millón de dólares. En Colombia, si bien se paga sobre 1,5 millones de dólares, el monto exento es, como máximo, 140.500 dólares (Londoño-Vélez y Ávila-Mahecha, 2018), lo que ha traído problemas en el corte, cuestión que el diseño aquí propuesto corrige.

- Los diversos tipos de activos de propiedad de personas con fortunas superiores a 5 millones de dólares se gravan a la misma tasa, lo que disminuye los espacios de evasión por medio de transferencias entre activos. 
- El impuesto que se propone se debe aplicar al total de las fortunas globales, ya sea que se encuentren en el país o en el exterior, usando una misma tasa.

- A diferencia de todos los países que han introducido impuestos al patrimonio en el pasado, el sistema aquí propuesto se focaliza en un grupo muy reducido de personas (un 0,07\% de la población). Esto permite evitar que la inmensa mayoría de la población se vea afectada (lo que, a su vez, evita el rechazo social) y también permite focalizar de manera eficiente la fiscalización. En dos tercios de los países examinados, estos impuestos afectan a las capas medias. Pese a ello, siguen vigentes y en Suiza y el Uruguay (los dos países más relevantes en este sentido) recaudan un alto volumen de recursos que llega al 3,90\% y casi al 5\% de la recaudación impositiva total, respectivamente (OCDE, 2019a).

- Los países que tienen solo una tasa impositiva, tienen otros impuestos corporativos y personales altísimos (Noruega) o un monto exento alto (Bélgica). La gran mayoría de los países presenta dos o más tasas impositivas. Aquí se propone un sistema con dos tasas impositivas o, alternativamente, una tasa única, lo que permite una gran simplicidad para la fiscalización del impuesto.

- Muchos países, con la excepción de Colombia, tienen una distribución de la riqueza e ingresos mucho menos desigual que Chile. En contraste, Chile tiene bajos niveles de impuesto a la renta, casi no aplica regalías y la mayoría de las ganancias de capital en el país están exentas de todo impuesto. En general, la legislación chilena trata los ingresos del capital de manera mucho más favorable que en la mayoría de los países que tienen impuestos patrimoniales. Esto hace que los impuestos a la riqueza financiera en Chile sean mucho más necesarios que en países que tienen impuestos a los flujos de ingreso mayores y que tratan a los ingresos provenientes del capital de una manera menos favorable que Chile.

- Cuando estos impuestos han sido bien diseñados, su elusión y evasión han sido muy reducidas. Mientras estuvieron vigentes en Suecia y Dinamarca, países donde el secreto bancario está limitado, los niveles de recaudación efectiva se situaron por encima del 98\% de la recaudación teórica o potencial (véanse Seim, 2017, y Jakobsen otros, 2019). Aun en Colombia, donde la implementación ha sido más imperfecta, los niveles de elusión y evasión han sido relativamente modestos (Londoño-Vélez y Ávila-Mahecha, 2018).

Para asegurar una adecuada fiscalización se recomienda que un departamento especial del Servicio de Impuestos Internos (SII) se dedique al control y la supervisión de este impuesto. Se sugiere que se exija una declaración jurada formal de todos los activos y que se establezcan penas muy duras para quienes evadan estos impuestos. A los efectos de la valoración de los diferentes activos, se recomienda utilizar la fórmula de valoración de activos usada por Suiza, que ha sido reconocida como muy exitosa y precisa. Se debe pedir a las instituciones financieras que cada año brinden al SIl información sobre depósitos a plazo, bonos, cuentas corrientes, acciones a valor de mercado, fondos mutuos y otros. Además, siguiendo el ejemplo de Suiza, el SIl debe desarrollar un mecanismo sistemático de información sobre la valoración de los activos. La valoración de activos físicos puede hacerse usando los catastros oficiales de las municipalidades sobre propiedades, lo que incluye tierras y bosques. Además, existen registros de fácil acceso sobre vehículos motorizados, aviones, helicópteros y yates.

Saez y Zucman (2019a) indican que la composición de la riqueza entre los muy ricos es diferente que entre los ciudadanos promedio: el $80 \%$ de la riqueza que posee el $0,1 \%$ superior corresponde a acciones, bonos y bienes raíces, cuya medición y valoración son bastante fáciles. 


\section{Medidas complementarias para el cumplimiento}

\section{a) Transparencia tributaria e intercambio de información internacional}

Una gran preocupación en lo que respecta a la aplicación de estos impuestos tiene que ver con la posibilidad de ocultar activos en otros países, particularmente en paraísos fiscales. Al respecto, es importante entender que existe una amplia red internacional de periodistas dedicados a descubrir cuentas en paraísos fiscales, exponiendo nombres y volumen de activos ocultos en ellos. Además, hay una tendencia mundial a poner límites a estos paraísos fiscales y a transparentar las cuentas que allí existen.

La OCDE ha creado un sistema de transparencia tributaria de intercambio de información financiera internacional que facilita enormemente el control de la evasión tributaria al permitir identificar las fuentes originales de grandes fortunas escondidas bajo diferentes subterfugios (OCDE, 2019b). Ocultar activos usando entramados societarios de gran complejidad es extremadamente difícil en la medida en que los países utilicen los medios que este sistema de información provee. Chile debe usar este sistema de una manera mucho más intensa de lo que lo ha hecho para reducir drásticamente la evasión tributaria de los diversos impuestos a la renta y de un eventual impuesto patrimonial. Este sistema permite tanto la solicitud unilateral de información como la cooperación bilateral o multilateral.

Según la Financial Transparency Coalition (FTC, s/f), los informes país por país necesitarían que las multinacionales compartan esta información para cada país donde operan. La información daría a los gobiernos una capacidad mucho mayor para detectar actividades irregulares que deberían investigarse más a fondo, incluidos, por ejemplo, casos de corrupción y soborno. Se debe exigir a las empresas multinacionales que publiquen información de informes país por país porque este problema global ha demostrado ser demasiado grande para que los gobiernos nacionales los gestionen solos. Los periodistas, las organizaciones de la sociedad civil y los académicos han sensibilizado al público sobre la escala de evasión y elusión de impuestos, y son fundamentales para analizar no solo el problema, sino también las posibles soluciones.

Por último, cabe mencionar el acuerdo recíproco de información financiera entre bancos y otras instituciones de los Estados Unidos y varios países latinoamericanos, incluido Chile (la llamada Ley de Cumplimiento Tributario de Cuentas Extranjeras) ${ }^{11}$.

\section{b) Declaración jurada}

Resulta clave disponer de una declaración a los fines de control. Por ello es muy importante tener en cuenta algunos aspectos (Benítez y Velayos, 2018):

- El diseño tiene que ser estable en el tiempo, ya que los cambios, sobre todo si son muy radicales, dificultan la comparación intertemporal.

- Tiene que dividirse en secciones que permitan conocer distintas categorías de patrimonio y también las deudas (pues estas pueden distorsionar el control).

- El diseño de la declaración debe coordinarse con la del impuesto a la renta. Un ejemplo sería el ahorro previsional privado, cuyas ganancias acumuladas suelen quedar exoneradas del impuesto a la renta y que podría declararse en sección independiente en la declaración

\footnotetext{
${ }^{11}$ Véase un análisis exhaustivo, elaborado por dos connotados economistas de la Universidad de California Berkeley para el caso de los Estados Unidos, particularmente de los mecanismos que se deben poner en marcha para una correcta aplicación de un impuesto patrimonial, en Saez y Zucman (2019a).
} 
de patrimonio, de modo que los datos ligados a esta parte no perjudiquen los cruces de información con las declaraciones de impuesto a la renta.

- Debe mantenerse la generalidad de declarantes, la universalidad del patrimonio (con muy pocas excepciones) y la capacidad de actualización de su valoración mediante el empleo de criterios eficientes.

\section{c) Secreto bancario y tributario}

Un aspecto fundamental, que en parte determina el éxito recaudatorio tanto de este impuesto como de los impuestos a la renta, es la limitación significativa del secreto bancario.

Suiza es un ejemplo donde, debido al secreto bancario, no hay informes de terceros sobre la riqueza financiera. De acuerdo con Brülhart y otros (2016), esto ha generado una subdeclaración de la riqueza de entre el $23 \%$ y el $34 \%$.

De acuerdo con OCDE (2019c), diez años después de que el Grupo de los 20 (G20) declarara el fin del secreto bancario, la comunidad internacional ha logrado un éxito sin precedentes en el uso de nuevos estándares de transparencia para combatir la evasión fiscal en el extranjero. El intercambio automático de información corresponde a la transmisión sistemática y periódica de información fiscal por parte de los países al país de residencia en relación con diversas categorías de ingresos, como dividendos, intereses, ingresos brutos, regalías, salarios y pensiones. El Estándar para el Intercambio Automático de Información sobre Cuentas Financieras se estableció en 2014 con el propósito de poner fin al secreto bancario. Hoy, más de 90 jurisdicciones intercambian información de cuentas financieras de forma automática, y hasta el momento se han recuperado más de 95.000 millones de euros gracias a este sistema. Como resultado, hasta la fecha se han intercambiado datos de 84 millones de cuentas en el extranjero, con un valor total de alrededor de 10.000 millones de euros (OCDE, 2019d).

Chile cuenta desde 2009 con una ley que permite el acceso a la información bancaria protegida con secreto o reserva por parte de la autoridad tributaria ${ }^{12}$. Si bien esta ley flexibiliza el secreto bancario, todavía es extremadamente difícil tener acceso a información de las cuentas bancarias. El Servicio de Impuestos Internos (SII) puede acogerse a esta ley solo cuando pueda demostrar que es indispensable la verificación de la veracidad e integridad de las declaraciones de impuestos o la falta de dichas declaraciones (Brokering Abogados, 2020).

Para lidiar de mejor forma con el patrimonio ubicado dentro y fuera del país, y así aumentar considerablemente su eficacia, Chile debe suscribir al estándar mundial de la OCDE y suprimir el secreto bancario, medida que ha sido un éxito en los países que la han adoptado ${ }^{13}$.

\footnotetext{
12 Véase Biblioteca del Congreso Nacional de Chile (BNC), "Ley 20406: establece normas que permiten el acceso a la información bancaria por parte de la autoridad tributaria", 2009 [en línea] https://www.bcn.cl/leychile/navegar?idNorma=1008772.

${ }^{13}$ En el libro Empresarios zombis: la mayor elusión tributaria de la elite chilena, Guzmán y Rojas (2017) efectúan un estudio periodístico acabado sobre la elusión de impuestos por parte de grandes grupos económicos en Chile. Como dice uno de los autores, estos grupos no solo eludieron impuestos, sino que además concentraron la riqueza. En la investigación descubrieron elusiones de grandes montos a través de múltiples estrategias tributarias y van aún más allá, ya que establecen una lúcida conexión entre las estrategias de elusión y la profunda desigualdad económica del país. Un aspecto de suma relevancia consistió en el secreto tributario. En palabras de los autores: "una investigación como esta no habría sido posible sin que muchas fuentes consideraran que el secreto tributario debía ser dejado de lado para que la opinión pública conociera una historia que en esencia había permanecido oculta durante casi una década" (Guzmán y Rojas, 2017, pág. 10).
} 


\section{Externalidades positivas de los impuestos patrimoniales no tradicionales}

Independientemente de la magnitud de la recaudación, los impuestos al patrimonio generan incentivos económicos y tributarios de gran relevancia. A continuación se destacan dos de los principales.

\section{a) Productividad, competencia e innovación}

En algunos artículos de Guvenen y otros (2019) y Shakow y Shuldiner (2000) se muestra que un impuesto sobre el patrimonio puede fomentar una mayor innovación. Los autores sostienen que respecto de los impuestos a la riqueza (impuestos patrimoniales no tradicionales, los empresarios que tienen niveles de riqueza similares pagan impuestos similares, independientemente de su productividad. Esto significaría que el impuesto a la riqueza tendría un impacto relativo mayor sobre la riqueza improductiva, lo que incentivaría a sus propietarios a desplegar sus activos productivamente en busca de un mayor rendimiento ${ }^{14}$.

Saez y Zucman (2019b) muestran que un impuesto sobre el patrimonio con un umbral de 50 millones de dólares en los Estados Unidos solo se aplicaría a alrededor del 1\% del acervo total de riqueza de los hogares. Los autores señalan que el aumento del ahorro del resto de la población (como resultado del descenso de la desigualdad) y del gobierno podría compensar cualquier reducción en el acervo de capital. En términos de efectos sobre la innovación, indican que la mayor parte de la innovación la producen personas jóvenes y no ricas (los ricos tienden a ser mucho mayores que el promedio), que no se verían afectadas por un impuesto a la riqueza de alta exención. Además, sostienen que las empresas establecidas gastan recursos para proteger sus posiciones dominantes en el mercado, lo que reduce la innovación. Como resultado, un impuesto al patrimonio que solo recauda impuestos de los dueños de empresas ya establecidos podría aumentar la competencia y, por lo tanto, la innovación.

\section{b) Sinergia con el impuesto a los ingresos}

Los impuestos al patrimonio se gravan sobre el acervo de patrimonio sobre una base devengada, mientras que los impuestos sobre la renta se gravan sobre el flujo producto del acervo de patrimonio. Una tasa impositiva baja sobre el patrimonio es equivalente a un impuesto sobre la renta de tasa alta. Al analizar un plan de impuestos sobre el patrimonio debe considerarse la interacción entre los impuestos sobre el patrimonio y los impuestos sobre la renta existentes ${ }^{15}$.

Contar con un sistema mixto permite mejorar la recaudación del impuesto al ingreso (o a la renta), sobre todo para las personas que obtienen ganancias de capital. Tanto la declaración de patrimonio como su fiscalización deben ser coherentes con la rentabilidad obtenida como dividendos y declarada en el impuesto a los ingresos. Esto reduciría significativamente las pérdidas por elusión o evasión de impuestos en los tramos más ricos de ingreso.

\footnotetext{
${ }^{14}$ Véase una discusión más profunda al respecto en el artículo del economista Garret Watson (Watson, 2019).

15 Véanse más detalles en Li (2019).
} 


\section{EL modelo}

En esta sección se propone una metodología para estimar los patrimonios de los grupos de más altos ingresos, que son los que normalmente interesan para establecer impuestos patrimoniales no tradicionales. Se consideran las fuentes de datos patrimoniales más importantes disponibles para un grupo grande de países, particularmente provistas por The Boston Consulting Group (BCG) (Beardsley y otros, 2015; Zakrzewski y otros, 2018) y Credit Suisse Research Institute (2019), que a menudo pueden complementarse con fuentes locales. Los datos disponibles más precisos corresponden a la distribución del patrimonio financiero de los diversos grupos de la población en cada país. Para estimar el patrimonio total de los grupos más ricos es necesario utilizar información indirecta. Por esta razón, la metodología propuesta a continuación parte de los datos de patrimonio financiero que son los más precisos, y de ahí se sugiere una metodología para estimar la riqueza total de los grupos más ricos. Por último, se propone una metodología para estimar la recaudación tributaria de los impuestos patrimoniales no tradicionales.

\section{Patrimonio financiero y patrimonio total ${ }^{16}$}

Siguiendo la metodología de The Boston Consulting Group (Zakrzewski y otros, 2018), se define el patrimonio financiero como el patrimonio de las personas, excluida su participación mayoritaria en empresas y todos los activos inmobiliarios.

Se definen las siguientes variables:

$X_{i, j}^{t} \quad$ Grupo que contiene un número de personas que poseen un patrimonio financiero entre $i$ y $j$ unidades monetarias, en el año $t$. Con $i=0,1, \ldots$, y $j=1, \ldots, \infty$.

$f\left(X_{i, j}^{t}\right)$ Patrimonio financiero asociado al grupo $X_{i, j}^{t}$.

$c\left(X_{i, j}^{t}\right)$ Fracción del patrimonio financiero con respecto al patrimonio total asociado a $X_{i, j}^{t}$ con $c \in(0,1)$.

$p\left(X_{i, j}^{t}\right) \quad$ Patrimonio total asociado al grupo $X_{i, j}^{t}$.

El patrimonio total del grupo de personas $X_{i, j}^{t}$ se puede escribir como:

$$
p\left(X_{i, j}^{t}\right)=\frac{f\left(X_{i, j}^{t}\right)}{c\left(X_{i, j}^{t}\right)}
$$

Las variables $X_{i, j}^{t}$ y $f\left(X_{i, j}^{t}\right)$ en principio se asumen conocidas para el período $t$; en el caso contrario, es posible estimarlas sobre la base de la información de algún período anterior ${ }^{17}$.

Si para el período $t$ no se conoce $X_{i, j}^{t}$ pero sí se conoce $X_{s, j}^{t}$, con $s<i$, y para el período $t$ - $h$ se conoce $X_{i, j}^{t-h}$ y $X_{s, j}^{t-h}$, el estimador de esta variable $\left(\hat{X}_{i, j}^{t}\right)$ será:

$$
\hat{X}_{i, j}^{t}=X_{s, j}^{t} \frac{X_{i, j}^{t-h}}{X_{s, j}^{t-h}}
$$

\footnotetext{
${ }^{16} \mathrm{~A}$ lo largo de este trabajo, siempre que se habla de patrimonio, sea financiero o total, se hace referencia a activos menos pasivos, esto es, riqueza neta.

${ }^{17}$ En caso de que no se cuente con información de períodos anteriores, o que esta no sea adecuada, se puede calcular $\hat{X}_{i, j}^{t}$ y $f\left(\hat{X}_{i, j}^{t}\right)$ sobre la base de la distribución de Pareto, siguiendo una metodología similar a la presentada en la sección V.2.
} 
Si ocurre lo mismo para $f\left(X_{i, j}^{t}\right)$, el estimador será:

$$
f\left(\hat{X}_{i, j}^{t}\right)=f\left(X_{s, j}^{t}\right) \frac{f\left(X_{i, j}^{t-h}\right)}{f\left(X_{s, j}^{t-h}\right)}
$$

Por otra parte, sobre la base de considerar el patrimonio total (no solo el financiero), las personas que estaban en un tramo $i-j$ de acuerdo con su patrimonio financiero pasan a estar en un tramo superior (de patrimonio total) mayor, $k-l$. Esta metodología asume que es posible calcular el límite inferior $(k)$ y superior $(I)$ del nuevo tramo sobre la base del factor $c\left(X_{i, j}^{t}\right)$. En otras palabras, personas que, clasificadas por patrimonio financiero, están en el tramo $i-j$, estarán en un tramo superior cuando se considera patrimonio total. Así:

$k(i)$ Monto en unidades monetarias para el límite inferior del tramo que considera patrimonio total, con $i$ límite inferior del tramo que considera patrimonio financiero, donde $k>i$.

$I(j)$ Monto en unidades monetarias para el límite superior del tramo que considera patrimonio total, con $i$ límite superior del tramo que considera patrimonio financiero, donde $l>j$.

Donde,

$$
\begin{aligned}
& k(i)=\frac{i}{c\left(X_{i, j}^{t}\right)} \\
& l(j)=\frac{j}{c\left(X_{i, j}^{t}\right)}
\end{aligned}
$$

\section{Redefinición de grupos en virtud del patrimonio total}

Se definen las siguientes variables para clasificar a las personas sobre la base de su patrimonio total neto.

$Y_{i, j}^{t} \quad$ Grupo $\left(\mathrm{N} .{ }^{\circ}\right)$ de personas que poseen un patrimonio total ente $i$ y $j$ unidades monetarias, en el año $t$. Con $i=0,1, \ldots$, l y $j=1, \ldots, \infty$.

$Y_{i, k}^{t} \quad$ Grupo $\left(\mathrm{N} .^{\circ}\right)$ de personas que poseen un patrimonio total ente $i$ y $k$ unidades monetarias, en el año $t$. Con $k$ de ecuación (4) y $k>i$.

$Y_{j, l}^{t} \quad$ Grupo $\left(\mathrm{N} .^{\circ}\right)$ de personas que poseen un patrimonio total ente $j$ y $l$ unidades monetarias, en el año $t$. Con $l$ de ecuación (5) y $l>j$.

De esta forma, $Y_{i, j}^{t}$ corresponderá a las personas con patrimonio financiero entre $i$ y $j, X_{i, j}^{t}$, más las que se incorporan $Y_{i, k}^{t}$, menos las que salen $Y_{j, l}^{t}$ (algunas personas pueden salir del grupo para ingresar a uno superior). Así:

$$
Y_{i, j}^{t}=X_{i, j}^{t}+Y_{i, k}^{t}-Y_{j, l}^{t}
$$

El patrimonio total asociado a $Y_{i, j}^{t}$ corresponderá a $p\left(Y_{i, j}^{t}\right)$, expresado como:

$$
p\left(Y_{i, j}^{t}\right)=p\left(Y_{i, j}^{t}\right)+p\left(Y_{i, k}^{t}\right)-p\left(Y_{j, l}^{t}\right)
$$

Para un tramo cualquiera de patrimonio total, no necesariamente se conoce el número de personas, el monto de la riqueza ni su distribución entre las personas debido a las limitaciones de las fuentes de información. Para lidiar con esta restricción se utilizan aproximaciones metodológicas que se detallan a continuación. 
Se asume que la distribución del patrimonio total dentro de los tramos se puede representar por la distribución de Pareto, que se comporta de buena forma en los tramos altos de la distribución del ingreso y la riqueza (López, Figueroa y Gutiérrez, 2016; Atkinson, 2007). Esta distribución se escribe de la siguiente manera (adaptada a patrimonio total):

$$
N=A\left(\frac{z_{m}}{Z}\right)^{\alpha}=A \cdot z_{m}^{\alpha} \cdot z^{-\alpha}
$$

Donde:

$N \quad$ Número de personas que tienen un patrimonio total mayor a $z$.

A Número total de personas.

z $\quad$ Patrimonio total en unidades monetarias de las personas.

$z_{m} \quad$ Monto más bajo de patrimonio asociado a una persona en este grupo.

$\alpha \quad$ Parámetro asociado al nivel de desigualdad de patrimonio.

De esta forma, es posible estimar la cantidad de personas que poseen un patrimonio total entre $i$ y $k$, así como de aquellas que tienen un patrimonio entre $j$ y $l$.

$$
\begin{gathered}
Y_{i, k}^{t}=A \cdot z_{m}{ }^{\alpha} \cdot\left(k^{-\alpha}-i^{-\alpha}\right) \\
Y_{j, l}^{t}=A \cdot z_{m}^{\alpha} \cdot\left(l^{-\alpha}-j^{-\alpha}\right)
\end{gathered}
$$

El patrimonio total de las personas con patrimonio superior a un valor $w>z_{m}$ y menor a un valor $M>w, P_{w, M}(N)$ se estima utilizando la función de densidad de la distribución de Pareto de la siguiente forma (partiendo de la ecuación (9)):

$$
P_{w, M}(N)=\int_{w}^{M} \frac{d N}{d z} \cdot z \cdot d z=A \cdot z_{m}{ }^{\alpha} \int_{w}^{M} z^{-\alpha} \cdot d z
$$

Sobre la base de las ecuaciones (6), (7), (9), (10) y (11), se obtienen los valores de $Y_{i, j}^{t}$ y $p\left(Y_{i, j}^{t}\right)$, logrando así una correcta redefinición de los grupos de interés.

$$
Y_{i, j}^{t}=X_{i, j}^{t}+A \cdot z_{m}^{\alpha} \cdot\left(k^{-\alpha}-i^{-\alpha}-l^{-\alpha}+j^{-\alpha}\right)
$$

El patrimonio total asociado a $Y_{i, j}^{t}$ corresponderá a $p\left(Y_{i, j}^{t}\right)$ expresado como:

$$
p\left(Y_{i, j}^{t}\right)=p\left(X_{i, j}^{t}\right)+A \frac{\alpha}{1-\alpha} z_{m}^{\alpha} \cdot \alpha\left(k^{1-\alpha}-i^{1-\alpha}-j^{1-\alpha}+l^{1-\alpha}\right)
$$

\section{Patrimonio total actualizado}

Una fracción del patrimonio total de cada grupo corresponde al patrimonio bursátil, que está sujeto a variaciones. Estas variaciones se producirán durante el período $t+1$ para el grupo con patrimonio total asociado al período $t\left(Y_{i, j}^{t}\right)$. Se definen las siguientes variables: 
$b\left(Y_{i, j}^{t}\right) \quad$ Fracción del patrimonio bursátil asociado a $Y_{i, j}^{t} \operatorname{con} b\left(Y_{i, j}^{t}\right) \in(0,1)$

$\Delta_{t+1}\left(Y_{i, j}^{t}\right)$ Variación porcentual del patrimonio bursátil asociado a $Y_{i, j}^{t}$, durante el período $t+1$.

De esta forma se puede escribir el patrimonio total actualizado de cada grupo en el período $t+1$, considerando las variaciones bursátiles como:

$$
R_{t+1}\left(Y_{i, j}^{t}\right)=p\left(Y_{i, j}^{t}\right) \cdot\left[1-b\left(Y_{i, j}^{t}\right) \cdot \Delta_{t+1}\left(Y_{i, j}^{t}\right)\right]
$$

\section{Impuesto patrimonial}

El monto $R_{t+1}\left(Y_{i, j}^{t}\right)$ corresponde a la base imponible para la aplicación del impuesto al patrimonio del grupo $Y_{i, j}^{t}$, para el período $t+1$. Se definen las siguientes variables:

$\tau_{i, j} \quad$ Tasa impositiva para el tramo $i-j$, con $\tau_{i, j} \in(0,1)$.

$u_{*} \quad$ Monto exento del pago de impuesto en unidades monetarias.

$\varepsilon\left(Y_{i, j}^{t}\right) \quad$ Pérdidas por evasión asociadas a la recaudación del impuesto sobre el patrimonio total actualizado del grupo $Y_{i, j}^{t}$, con $\varepsilon\left(Y_{i, j}^{t}\right) \in(0,1)$.

$W_{t+1}\left(Y_{i, j}^{t}\right)$ Recaudación efectiva asociada al grupo $Y_{i, j}^{t}$, durante el período $t+1$.

$T_{t+1} \quad$ Recaudación efectiva total para el período $t+1$.

Se supone la existencia de dos grupos (clasificados por tramo de patrimonio total) y una tasa impositiva única. De esta se tendrá una tasa $\tau$ tal que:

$$
\tau_{u_{*}, m}=\tau_{m, \infty}=\tau
$$

En este caso, la recaudación sobre el patrimonio de cada uno de estos dos grupos se obtiene reemplazando (18) en (15) y (16). La recaudación total corresponde a la suma de ambas.

$$
\begin{gathered}
W_{t+1}\left(Y_{u *, m}^{t}\right)=\left[R_{t+1}\left(Y_{u *, m}^{t}\right)-Y_{u *, m}^{t} \cdot u_{*}\right] \cdot \tau \cdot\left[1-\varepsilon\left(Y_{u *, m}^{t}\right)\right] \\
W_{t+1}\left(Y_{m, \infty}^{t}\right)=\left[R_{t+1}\left(Y_{m, \infty}^{t}\right)-Y_{m, \infty}^{t} \cdot u_{*}\right] \cdot \tau \cdot\left[1-\varepsilon\left(Y_{m, \infty}^{t}\right)\right]
\end{gathered}
$$

\section{Aplicación al caso de Chile}

En esta sección se aplica la metodología desarrollada en la sección anterior al caso de Chile. Este ejercicio es importante como una guía para políticas de impuestos patrimoniales en Chile y como una ilustración que puede ser útil para la aplicación de estos impuestos en otros países.

El modelo se aplica para estimar el patrimonio total actualizado de dos grupos que se han definido -ricos (entre 5 millones de dólares y 100 millones de dólares) y superricos (sobre 100 millones de dólares) - y para determinar la recaudación potencial de un impuesto patrimonial. 
El procedimiento es el siguiente ${ }^{18}$ :

- Las ecuaciones (1), (2) y (3) permiten obtener el patrimonio financiero a 2018 en virtud de la información de The Boston Consulting Group (Beardsley y otros, 2015; Zakrzewski y otros, 2018) y de los datos dados a conocer por Credit Suisse Research Institute (2019).

- Sobre la base de las ecuaciones (4) a (13) se obtiene el patrimonio total para los grupos clasificados como ricos y superricos en este estudio. Respecto de los coeficientes utilizados en la estimación en virtud de la distribución de Pareto se han definido dos casos, para los cuales se ha calibrado el coeficiente sobre la base de los datos existentes. La separación de estos dos casos se sustenta en la gran asimetría existente en los grupos de mayor riqueza, razón por la cual, cuando se quiere estimar la distribución en un grupo, se debe considerar el tramo de riqueza más alto posible. A medida que aumenta el tramo de riqueza, mayor es el coeficiente de Pareto (Atkinson, 2007; López, Figueroa y Gutiérrez, 2016). Además, cuando no se cuenta con información para calibrar el coeficiente, se utiliza información existente en la literatura, con valores superiores a 1,5, llegando hasta 3,0 para tramos de riqueza muy alta (Atkinson, 2007; Clementi y Gallegati, 2005). De esta forma, los dos casos corresponden a los siguientes:

- Personas con patrimonio total sobre 1 millón de dólares. El coeficiente de Pareto calibrado corresponde a 0,8919.

- Personas con patrimonio total sobre 5 millones de dólares. El coeficiente de Pareto calibrado corresponde a 1,25.

- Las ecuación (14) permite estimar el patrimonio total actualizado a fines de 2019, considerando las fluctuaciones bursátiles desde fines de 2018 de una parte del patrimonio de los grupos de interés. La fracción del patrimonio bursátil asociado a ambos grupos se ha estimado sobre la base de Echeverría, Valdivia y Acuña (2020). La variación del patrimonio bursátil se estima de acuerdo con el índice de la Bolsa de Comercio de Santiago, empresas que integran el índice de precios selectivos de las acciones (IPSA), durante 2019 (Bolsa de Comercio de Santiago, 2020).

En el cuadro 2 se muestra el patrimonio total actualizado para los grupos de los ricos y los superricos.

\section{Cuadro 2}

Patrimonio total actualizado, 2019

\begin{tabular}{lcccc}
\hline Grupo & $\begin{array}{c}\text { Tramo } \\
\text { (en millones de dólares) }\end{array}$ & Número de personas & $\begin{array}{c}\text { Patrimonio total actualizado } \\
\text { (en millones de dólares) }\end{array}$ & $\begin{array}{c}\text { Per cápita } \\
\text { (en millones de dólares) }\end{array}$ \\
\hline Ricos & $5-100$ & 8900 & 113716 & 12,8 \\
\hline Superricos & $100-\infty$ & 263 & 150444 & 572,0 \\
\hline Total & - & 9163 & 264160 & - \\
\hline
\end{tabular}

Fuente: Elaboración propia, sobre la base de B. Beardsley y otros, Global Wealth 2015: Winning the Growth Game, Boston, The Boston Consulting Group (BCG), 2015; A. Zakrzewski y otros, Global Wealth 2018: Seizing the Analytics Advantage, Boston, The Boston Consulting Group (BCG), 2018; Credit Suisse Research Institute, Global Wealth Databook 2019, Zúrich, 2019; Bolsa de Comercio de Santiago, Memoria anual 2019, 2020 (en línea) https://servicioscms. bolsadesantiago.com/Noticiascibe/Avisos\%20Generales/Memoria\%20Bolsa\%20de\%20Santiago\%202019.pdf, y C. Echeverría, C. Valdivia y G. Acuña, "Ranking de grupos económicos RGE 2018", Santiago, Universidad del Desarrollo (UDD), 2020 (en línea) https://ceen.udd.cl/files/2020/02/RGE-18-12vf-2.pdf.

\footnotetext{
18 Véase el detalle de la aplicación, paso por paso, del modelo al caso de Chile en López y Sturla (2020).

19 Para este caso se consideró una distribución de Pareto truncada.
} 


\section{Sistema impositivo y recaudación}

Se propone un gravamen único equivalente al 2,5\%. Usando los resultados de Londoño-Vélez y Ávila-Mahecha (2018) para Colombia, que estimaron una tasa de subreporte de la riqueza igual al $3 \%$ por cada $1 \%$ de impuesto patrimonial, se obtiene un subreporte total del $7,5 \%$. El monto de la riqueza total declarada será entonces de 244.348 millones de dólares.

Descontando al monto anterior el total exento, esto es, 5 millones de dólares para un total 9.163 personas (45.815 millones de dólares), la riqueza afecta al impuesto corresponde a 198.533 millones de dólares. Al aplicar la tasa del 2,5\% se obtiene una recaudación de 4.963 millones de dólares.

De manera equivalente, usando las ecuaciones (15), (16) y (17) del modelo, y considerando una pérdida por evasión del 7,5\%, se obtienen los resultados incluidos en el cuadro 3.

Cuadro 3

Recaudación efectiva, con tasa impositiva única del 2,5\%

\begin{tabular}{lcc}
\hline Grupo & Número de personas & $\begin{array}{c}\text { Recaudación efectiva } \\
\text { (en millones de dólares) }\end{array}$ \\
\hline Ricos & 8900 & 1491 \\
\hline Superricos & 263 & 3472 \\
\hline Total & 9163 & 4963 \\
\hline
\end{tabular}

Fuente: Elaboración propia.

\section{Conclusiones}

Se ha elaborado un modelo para estimar el patrimonio de los grupos más ricos de un país. La metodología permite obtener resultados a pesar de las limitaciones de la información existente en la mayoría de los casos. Además, se ha hecho un análisis exhaustivo de los impuestos patrimoniales y se ha demostrado que, cuando estos impuestos están bien diseñados, las típicas críticas que se han hecho sobre ellos tienen escasa validez. Más aún, se ha demostrado que los impuestos patrimoniales no solo contribuyen a reducir las bases mismas de la desigualdad acentuada por el COVID-19, sino que también, en países donde no se gravan las rentas económicas, son un instrumento valioso para recuperar parte de esas rentas económicas de las que se han apropiado los superricos, y que muchas veces constituyen la base de la fortuna acumulada por ellos. Un principio elemental de justicia económica clama por la restitución de las rentas de las que se ha apropiado un pequeñísimo grupo de la sociedad a lo largo de muchas décadas de privilegios, que han sido permitidos -e incluso promovidos - por gobiernos comprometidos con los intereses de esas personas. También resulta claro que, al reducir los incentivos a la búsqueda de rentas económicas, los impuestos patrimoniales se transforman en un instrumento que disminuye las ineficiencias económicas.

El análisis comparado de los impuestos patrimoniales vigentes en otros países indica que un gravamen de este tipo en Chile es totalmente viable. Si bien es cierto que otros países tienen o han tenido tasas más bajas, es importante considerar que la gran mayoría de ellos tiene otros impuestos directos más altos que los que se aplican en Chile y un gasto fiscal sobre los 30 puntos porcentuales del producto (en comparación con los 21 puntos porcentuales del PIB de Chile).

En el Reino Unido, país conocido por su generosidad con las grandes fortunas, donde la crisis sanitaria amenaza con exacerbar las desigualdades, el impuesto patrimonial está en plena discusión. En una encuesta de YouGov publicada a mediados de mayo se indica que el $61 \%$ de los británicos están a favor de un impuesto sobre el patrimonio para las fortunas de más de 750.000 libras (950.000 dólares) (Vera, 2020). El monto es cinco veces más bajo que el propuesto en este trabajo, 
lo que ratifica que el sistema impositivo aquí diseñado asume mucho menos riesgo en ese sentido; esto puede no solo facilitar su aplicación, sino también generar mayor apoyo ciudadano.

Por otra parte, una encuesta realizada por el Centro Estratégico Latinoamericano de Geopolítica (CELAG, 2020) en mayo ha mostrado que un $72,8 \%$ de la población chilena está de acuerdo con un impuesto a las grandes fortunas.

En abril de 2020, el Fondo Monetario Internacional (FMI) instó a los gobiernos de todo el mundo a imponer nuevos impuestos sobre la riqueza para conseguir liquidez, e incluyó en su propuesta la rebaja de impuestos sobre los salarios y la realización de transferencias de efectivo a los más afectados (FMI, 2020). En enero, el FMI había afirmado que se debía combatir la desigualdad elevando el gasto social, financiado con impuestos en lo más alto de la distribución del ingreso. El organismo internacional indicó en ese momento que esta política no afectaría el crecimiento económico (Georgieva, 2020). El Financial Times (2020) recientemente ha hecho lo propio y en una editorial histórica del 3 de abril indicó que los impuestos a las rentas y a la riqueza debían estar presentes en la agenda redistributiva.

\section{Bibliografía}

AAICI (Agencia Argentina de Inversiones y Comercio Internacional) (2019), "El sistema tributario en la Argentina" [en línea] https://www.inversionycomercio.org.ar/docs/pdf/El_Sistema_Tributario_en_la_Argentina.pdf.

Accorsi, S. y G. Sturla (2019), "Una estimación de la renta económica en el mercado de las Isapres en Chile", serie Documentos de Trabajo, № 491, Santiago, Universidad de Chile, diciembre.

Arthur, F. y otros (2020), "'Millionaires for Humanity' sign on letter", Millionaires for Humanity [en línea] https:// www.millionairesforhumanity.com/.

Atkinson, A. (2007), "Measuring top incomes: methodological issues", Top Incomes over the Twentieth Century: a Contrast between Continental European and English-Speaking Countries, A. Atkinson y T. Piketty (eds.), Oxford, Oxford University Press.

Beardsley, B. y otros (2015), Global Wealth 2015: Winning the Growth Game, Boston, The Boston Consulting Group (BCG).

Benítez, J. y F. Velayos (2018), "Impuestos a la riqueza o al patrimonio de las personas físicas con especial mención a América Latina y El Caribe", Documentos de Trabajo, № 1, Panamá, Centro Interamericano de Administraciones Tributarias (CIAT).

Bolsa de Comercio de Santiago (2020), Memoria anual 2019 [en línea] https://servicioscms.bolsadesantiago. com/Noticiascibe/Avisos\%20Generales/Memoria\%20Bolsa\%20de\%20Santiago\%202019.pdf.

Brokering Abogados (2020), "Secreto bancario en Chile", 6 de mayo [en línea] https://www.brokering.cl/ secreto-bancario-en-chile/.

Brülhart, M. y otros (2016), "Taxing wealth: evidence from Switzerland", NBER Working Paper, № 22376, Cambridge, Oficina Nacional de Investigaciones Económicas, junio.

CELAG (Centro Estratégico Latinoamericano de Geopolítica) (2020), "Panorama político y social de Chile", mayo [en línea] https://www.celag.org/wp-content/uploads/2020/05/informe-chile-web.pdf.

CEPAL (Comisión Económica para América Latina y el Caribe) (2017), Panorama Fiscal de América Latina y el Caribe, 2017 (LC/PUB.2017/6-P), Santiago.

Clementi, F. y M. Gallegati (2005), "Power law tails in the Italian personal income distribution", Physica A: Statistical Mechanics and its Applications, vol. 350, N²-4.

CPI (Consejo de Políticas de Infraestructura) (2020), "Gobierno logra acuerdo con la oposición: se crea marco fiscal de US\$12 mil millones para 24 meses y se eleva Ingreso Familiar de Emergencia", 15 de junio [en línea] http://www.infraestructurapublica.cl/gobierno-logra-acuerdo-la-oposicion-se-crea-marco-fiscalus12-mil-millones-24-meses-se-eleva-ingreso-familiar-emergencia/.

Credit Suisse Research Institute (2019), Global Wealth Databook 2019, Zúrich.

Echeverría, C., C. Valdivia y G. Acuña (2020), "Ranking de grupos económicos RGE 2018", Santiago, Universidad del Desarrollo (UDD) [en línea] https://ceen.udd.cl/files/2020/02/RGE-18-12vf-2.pdf.

Financial Times (2020), "Virus lays bare the frailty of the social contract", 3 de abril [en línea] https://www. ft.com/content/7eff769a-74dd-11ea-95fe-fcd274e920ca. 
FMI (Fondo Monetario Internacional) (2020), "Cuestiones tributarias: panorama general”, Serie Especial sobre Políticas Fiscales en respuesta al COVID-19, 6 de abril [en línea] https://www.imf.org/en/Publications/ SPROLLs/covid19-special-notes\#fiscal.

FTC (Financial Transparency Coalition) (s/f), "Country by country reporting" [en línea] https://financialtransparency. org/issues/country-by-country-reporting/.

Georgieva, K. (2020), "Reducir la desigualdad para generar oportunidades", Diálogo a fondo, 7 de enero [en línea] https://blog-dialogoafondo.imf.org/?p=12536.

Guvenen, F. y otros (2019), "Use it or lose it: efficiency gains from wealth taxation", NBER Working Paper, № 26284, Cambridge, Oficina Nacional de Investigaciones Económicas, septiembre.

Guzmán, J. y J. Rojas (2017), Empresarios zombis: la mayor elusión tributaria de la elite chilena, Santiago, Editorial Catalonia.

INE (Instituto Nacional de Estadísticas) (2020), "Estadísticas" [en línea] https://www.ine.cl/estadisticas/.

Jakobsen, K. y otros (2019), "Wealth taxation and wealth accumulation: theory and evidence from Denmark", The Quarterly Journal of Economics, vol. 153, № 1, octubre.

KMPG International (2020), Tax Facts 2020: a Survey of the Norwegian Tax System [en línea] https://assets. $\mathrm{kpmg} / \mathrm{content} / \mathrm{dam} / \mathrm{kpmg} / \mathrm{no} / \mathrm{pdf} / 2020 / 03 /$ Tax-facts-2020_WEB.PDF.

Li, H. (2019), "Comparing wealth taxation and income taxes", Tax Foundation, 9 de diciembre [en línea] https://taxfoundation.org/comparing-wealth-taxes-and-income-taxes/\#: :text=More\%20simply\%2C\%20 wealth\%20taxes\%20are,flow\%20from\%20the\%20wealth\%20stock.

Londoño-Vélez, J. y J. Ávila-Mahecha (2018), "Can wealth taxation work in developing countries? Quasiexperimental evidence from Colombia", 29 de noviembre [en línea] https://eml.berkeley.edu/ saez/course/ londono-wealth2018.pdf.

López, R. y G. Sturla (2020), "Hiper fortunas y súper ricos: ¿por qué un impuesto al patrimonio hace sentido?”, serie Documentos de Trabajo, № 495, Santiago, Universidad de Chile, junio.

López, R., E. Figueroa y P. Gutiérrez (2016), "Fundamental accrued capital gains and the measurement of top incomes: an application to Chile", The Journal of Economic Inequality, vol. 14, № 4, octubre.

Murphy, K., A. Shleifer y R. Vishny (1993), "Why is rent-seeking so costly to growth?", The American Economic Review, vol. 83, № 2.

OCDE (Organización de Cooperación y Desarrollo Económicos) (2020), "Tax on property” [en línea] https:// data.oecd.org/tax/tax-on-property.htm\#: :text=Tax\%20on\%20property\%20is\%20defined,ownership\% 20or\%20transfer\%20of\%20property.\&text=This\%20indicator\%20relates\%20to\%20government,GDP\%20 and\%20of\%20total\%20taxation.

(2019a), "Revenue Statistics - OECD countries: comparative tables: comparative tables - OECD countries" [en línea] https://stats.oecd.org/Index.aspx?Queryld=21699.

- (2019b), "Transparency and exchange of information for tax purposes: multilateral co-operation changing the world, 10th Anniversary Report" [en línea] https://www.oecd.org/tax/transparency/global-forum-10years-report.pdf.

- (2019c), "International community has achieved unprecedented success fighting offshore tax evasion", 26 de noviembre [en línea] https://www.oecd.org/tax/transparency/international-community-has-achievedunprecedented-success-fighting-offshore-tax-evasion.htm. (2019d), "Tax transparency" [en línea] https://www.oecd.org/tax/beps/tax-transparency/.

- (2018), The Role and Design of Net Wealth Taxes in the OECD, OECD Tax Policy Studies, No 26, París.

Piketty, T. (2015), "Capital and wealth taxation in the 21st century", National Tax Journal, vol. 68, № 2, junio. (2005), "Top income shares in the long run: an overview", Journal of the European Economic Association, vol. 3, No 2-3.

Ruiz, S. (2020), "¿Quién paga la cuenta? Gravar la riqueza para enfrentar la crisis de la COVID-19 en América Latina y el Caribe", Nota Informativa de Oxfam, 27 de julio [en línea] https://oxfamilibrary.openrepository. com/bitstream/handle/10546/621033/bp-quien-paga-la-cuenta-covid-19-270720-es.pdf.

Saez, E. y G. Zucman (2019a), "Progressive wealth taxation", Brookings Papers on Economic Activity, septiembre [en línea] https://www.brookings.edu/wp-content/uploads/2020/10/Saez-Zuchman-final-draft.pdf. (2019b), "How would a progressive wealth tax work? Evidence from the economics literature", 5 de febrero [en línea] http://gabriel-zucman.eu/files/saez-zucman-wealthtaxobjections.pdf.

Schrager, A. (2020), "Conversations with E21: Wojciech Kopczuk on Wealth Taxes", E21, 12 de mayo [en línea] https://economics21.org/html/conversations-e21-wojciech-kopczuk-wealth-taxes-3541.html.

Seim, D. (2017), "Behavioral responses to wealth taxes: evidence from Sweden", American Economic Journal: Economic Policy, vol. 9, № 4, noviembre. 
Shakow, D. y R. Shuldiner (2000), "A comprehensive wealth tax", Tax Law Review, vol. 53, N 4, Nueva York, Universidad de Nueva York.

Strada, J. y otros (2020), "Impuesto a los grandes patrimonios: propuestas en Europa y América del Sur y debate sobre propuestas en Argentina en el contexto de la pandemia de COVID-19", Centro de Economía Política Argentina (CEPA), 27 de abril [en línea] https://centrocepa.com.ar/informes/250-impuesto-a-losgrandes-patrimonios-propuestas-en-europa-y-america-del-sur-y-debate-sobre-propuestas-en-argentinaen-el-contexto-de-la-pandemia-de-covid-19.html.

Sturla, G. y otros (2018), "La riqueza regalada a la gran minería del cobre en Chile: nuevas estimaciones, 2005-2014", Revista CEPAL, № 24 (LC/PUB.2018/5-P), abril.

Vera, D. (2020), "¿Impuesto a los más ricos?: la idea que gana terreno en el Reino Unido ante crisis del coronavirus", BioBioChile, 5 de junio [en línea] https://www.biobiochile.cl/noticias/internacional/europa/2020/06/05/ impuesto-los-mas-ricos-la-idea-gana-terreno-reino-unido-ante-crisis-del-coronavirus.shtml.

Watson, G. (2019), "Proponents of wealth taxation must consider its impact on innovation", Tax Foundation, 12 de noviembre [en línea] https://taxfoundation.org/wealth-tax-economic-impact/.

Zakrzewski, A. y otros (2018), Global Wealth 2018: Seizing the Analytics Advantage, Boston, The Boston Consulting Group (BCG). 